\title{
ANALISIS KELAYAKAN FINANSIAL KELAPA SAWIT RAKYAT DI DESA KARYA BERSAMA KECAMATAN PARENGGEAN KABUPATEN KOTAWARINGIN TIMUR (Studi Kasus Pada Usahatani Sawit Rakyat Ibu Hj. Sunarsih)
}

\author{
${ }^{1}$ Fery Kurniadi, ${ }^{2}$ Pordamantra, ${ }^{3}$ Betrixia Barbara \\ ${ }^{1}$ Alumnus Program Studi Agribisnis Fakultas Pertanian Universitas Palangka Raya \\ ${ }^{2,3}$ Staf Pengajar Program Studi Agribisnis Fakultas Pertanian Universitas Palangka Raya \\ E-mail: feryk77@gmail.com
}

\begin{abstract}
This research was conducted to know the general description of the smallholder palm oil plantation farming of Mrs. $\mathrm{Hj}$. Sunarsih in Karya Bersama Village and to analyze the financial feasibility of an oil palm plantation run by Mrs. Hj. Sunarsih. The research location was chosen purposively, namely Karya Bersama Village, Parenggean District, Kotawaringin Timur Regency based on the consideration that the most of population in Karya Bersama Village were their living in the agricultural and plantation sectors. Respondent of this research was Mrs. Hj. Sunarsih with consideration of smallholder palm oil plantation of Mrs. $\mathrm{Hj}$. Sunarsih had oil palm trees with the same age were 11 years with this area was 10 hectares and it was the largest in Karya Bersama Village. This research only took the tree age of 11 years palm oil trees planted by Mrs. Hj. Sunarsih in 2009. The data analysis method in this research was qualitative analysis which was processed descriptively based on the result of observation and financial analysis which was processed quantitatively. The result of this research of the financial feasibility analysis of Mrs. Hj. Sunarsih's oil palm farming during 11 years planting period showed that Mrs. Hj. Sunarsih deserves to be implemented. Based on the financial feasibility investment criteria as follow: a) NPV value at DF $6 \%$ (NPV > 0) namely Rp 458.477.970 ; b) The IRR value is more than the $6 \%$ interest rate on KUR Micro Bank BRI (IRR > i) namely $16,48 \%$; c) Gross B/C > 1 namely 1,68 ; d) Net B/C value > 1 namely 2,97; and the payback period is relatively fast namely 6,98 (6 years 11 months).
\end{abstract}

Keywords: Plantation, Oil palm farming, Financial feasibility

\section{PENDAHULUAN}

Kalimantan Tengah merupakan salah satu provinsi yang mengandalkan sektor pertanian, karena dari segi ketersediaan lahan dan sumber daya alam yang sangat mendukung untuk aktivitas pertanian. Kalimantan Tengah juga merupakan salah satu sentra perkebunan kelapa sawit terbesar di Indonesia setelah Provinsi Riau, Provinsi Sumatera Utara dan Provinsi Sumatera Selatan. Kelapa sawit merupakan komoditas perkebunan utama dan komoditas unggulan di Provinsi Kalimantan Tengah.

Dalam 5 tahun terakhir luas areal perkebunan kelapa sawit di Provinsi Kalimantan Tengah berfluktuasi namun cenderung mengalami peningkatan dengan rata-rata pertumbuhan sebesar $4,30 \%$ per tahun, walaupun pada tahun 2017 mengalami penurunan sebesar $-5,59 \%$ namun kembali naik sebesar $0,84 \%$ pada tahun 2018. Sementara pada produksinya 
cenderung terus meningkat dengan ratarata pertumbuhan sebesar $11,07 \%$ setiap tahunnya. Kemudian pada produktivitasnya menunjukkan pola yang berfluktuasi, dengan rata-rata pertumbuhan sebesar $0,75 \%$ per tahun.

Kabupaten Kotawaringin Timur merupakan salah salah satu kabupaten yang berada di Kalimantan Tengah yang memiliki luas areal dan produksi perkebunan kelapa sawit terbesar di Kalimantan Tengah. Sektor pertanian merupakan salah satu sektor penting di Kabupaten Kotawaringin Timur yang berperan sebagai sumber pertumbuhan ekonomi di setiap tahunnya. Pada tahun 2018 luas areal dan produksi perkebunan kelapa sawit Kabupaten Kotawaringin Timur menjadi yang terbesar di Provinsi Kalimantan Tengah dengan luas areal 411.102,38 Ha dan produksi sebesar 1.843.178,97 Ton CPO, serta produktivitas yang relatif lebih tinggi yaitu sebesar 4,68 Ton/Ha bila dibandingkan dengan rata-rata Provinsi Kalimantan Tengah yang hanya sebesar 4,17 Ton/Ha.

Salah satu kecamatan yang berada di Kabupaten Kotawaringin Timur adalah Kecamatan Parenggean yang merupakan penghasil kelapa sawit terbesar di Kabupaten Kotawaringin Timur dengan luas areal 5.425,76 hektar dan produksi 9.312,93 ton dengan tingkat produktivitas 4,59 Ton/Ha pada tahun 2018. Tingginya luas areal, produksi dan produktivitas perkebunan kelapa sawit di Kecamatan Parenggean disebabkan karena adanya kesesuaian faktor ekologis untuk membudidayakan tanaman kelapa sawit dan didukung oleh luas areal yang dapat dipergunakan bagi perkebunan kelapa sawit.

Desa Karya Bersama adalah salah satu desa yang ada di Kecamatan Parenggean, Kabupaten Kotawaringin Timur, yang merupakan desa yang mengandalkan tanaman perkebunan komoditas Kelapa Sawit sebagai salah satu mata pencaharian masyarakat desa setempat. Sebagian besar penduduk di Desa Karya Bersama bekerja sebagai karyawan swasta, wiraswasta dan petani. Kondisi alam di Desa Karya Bersama cukup layak dan sangat potensial untuk dilakukan pengembangan usaha komoditas kelapa sawit, namun karena keterbatasan modal dan kurangnya kemampuan teknis usahatani membuat petani di Desa Karya Bersama kurang maksimal dalam mengelola kebunnya.

Salah satu petani kelapa sawit rakyat yang ada di Desa Karya Bersama adalah Ibu $\mathrm{Hj}$. Sunarsih. Ibu Hj. Sunarsih memulai usahatani perkebunan kelapa sawitnya sejak tahun 2000 dengan total luasan lahan perkebunan kelapa sawit yang dimilikinya sebesar 32 hektar. Sedangkan bila dibanding dengan petani kelapa sawit rakyat lainnya rata-rata hanya memiliki luas lahan sebesar 5-15 hektar.

Selain itu Ibu Hj. Sunarsih memiliki pohon kelapa sawit yang usianya seragam (11 tahun) pada luasan lahan yang besar (10 hektar). Jika dibandingkan dengan petani kelapa sawit rakyat lainnya hanya $\mathrm{Ibu} \mathrm{Hj}$. Sunarsih yang memiliki pohon kelapa sawit yang usianya seragam dengan luasan lahan paling besar.

Produksi usahatani kelapa sawit rakyat milik Ibu $\mathrm{Hj}$. Sunarsih menjadi salah satu yang terbesar di Desa Karya Bersama dengan hasil produksi dalam satu bulan sebesar 40-45 ton TBS yang bila dibandingkan dengan rata-rata produksi petani kelapa sawit rakyat lainnya di Desa Karya Bersama hanya mencapai $10-15$ ton TBS dalam satu bulan.

Masalah finansial rata-rata banyak dialami oleh para petani kelapa sawit rakyat di Desa Karya Bersama, salah satunya kemampuan para petani untuk melakukan pemupukan terhadap tanaman kelapa sawit 
yang rata-rata hanya dilakukan 2 kali pemupukan dalam setahun oleh para petani kelapa sawit rakyat di Desa Karya Bersama, akan tetapi berbeda dengan kemampuan finansial yang dimiliki oleh Ibu $\mathrm{Hj}$. Sunarsih yang menjadi salah satu petani yang rutin melakukan pemupukan terhadap tanaman kelapa sawitnya dengan 4 kali pemupukan dalam setahun. Hal tersebut dikarenakan kemampuan finansial yang dimiliki Ibu $\mathrm{Hj}$. Sunarsih jauh lebih baik dibandingkan rata-rata petani lainnya di Desa Karya Bersama yang masih kurang mampu secara finansial dalam mengelola usahatani perkebunan kelapa sawitnya.

\section{METODE PENELITIAN}

Penelitian ini dilaksanakan di Desa Karya Bersama, Kecamatan Parenggean, Kabupaten Kotawaringin Timur. Penentuan lokasi tersebut dilakukan dengan cara sengaja (purposive), dengan pertimbangan daerah ini merupakan salah satu daerah di desa yang masyarakatnya bermata pencaharian sebagai petani kelapa sawit. Waktu pelaksanaan penelitian ini berlangsung selama 3 (tiga) bulan yaitu dari bulan Oktober sampai Desember tahun 2020. Kegiatan penelitian terhitung dari penyusunan usulan penelitian, seminar usulan penelitian, pengumpulan dan pengolahan analisis data penelitian hingga penyusunan hasil penelitian (skripsi).

Responden yang diambil dalam penelitian ini adalah $\mathrm{Ibu} \mathrm{Hj}$. Sunarsih dengan pertimbangan usahatani kelapa sawit rakyat $\mathrm{Ibu} \mathrm{Hj}$. Sunarsih memiliki pohon kelapa sawit yang usianya seragam paling banyak yaitu 11 tahun dengan luas lahan sebesar 10 hektar dan menjadi yang terbesar di Desa Karya Bersama. Penelitian ini hanya mengambil usia pohon sawit 11 tahun yang ditanam oleh Ibu $\mathrm{Hj}$. Sunarsih pada tahun 2009.

Data yang dikumpulkan dalam penelitian ini adalah data primer dan data sekunder. Data primer diperoleh melalui pengamatan dan wawancara secara langsung pada petani sampel serta observasi lapangan dengan bantuan daftar pertanyaan (kuesioner). Data sekunder diperoleh dari lembaga atau instansi terkait seperti Badan Pusat Statistik, Dinas Perkebunan Provinsi Kalimantan Tengah dan instansi terkait lainnya.

Data yang diperoleh peneliti dari lapangan melalui daftar pertanyaan (kuesioner) yang telah dijawab kemudian diedit dan diolah secara manual dengan cara tabulasi sederhana yang disesuaikan dengan tujuan penelitian. Data kuantitatif diolah dengan bantuan alat hitung. Data kualitatif diolah secara deskriptif dari hasil pengamatan di lapangan kemudian dijelaskan dalam bentuk kalimat untuk memberikan gambaran yang jelas tentang data tersebut. Analisis data yang digunakan untuk menjawab tujuan penelitian adalah sebagai berikut:

1. Untuk menjawab tujuan pertama dalam penelitian yaitu data yang telah dikumpulkan secara kualitatif dan akan langsung diuraikan secara deskriptif.

2. Untuk menjawab tujuan kedua dalam penelitian yaitu menganalisis kelayakan finansial usahatani kelapa sawit rakyat milik Ibu Hj. Sunarsih di Desa Karya Bersama Kecamatan Parenggean Kabupaten Kotawaringin Timur, yaitu menggunakan rumus sebagai berikut:

\section{a. Cash Flow Analysis}

\section{Biaya Total (Total Cost)}

$\mathrm{TC}=$ Biaya investasi $+\mathrm{FC}+\mathrm{VC}$

\section{Penerimaan Total (Total Revenue)}

$$
\mathrm{TR}=\mathrm{Pq} \cdot \mathrm{Q}
$$

\section{Keuntungan (Profit)}

$$
\pi=\mathrm{TR}-\mathrm{TC}
$$

Keterangan :

$$
\begin{aligned}
& \mathrm{TR}=\text { Total penerimaan } \\
& \mathrm{Q}=\text { Jumlah output } \\
& \mathrm{Pq}=\text { Harga output } \\
& \mathrm{TC}=\text { Total biaya } \\
& \mathrm{FC}=\text { Fix cost } \\
& \mathrm{VC}=\text { Variabel cost } \\
& \pi=\text { Keuntungan }
\end{aligned}
$$

\section{b. Net Present Value (NPV)}

$$
\mathrm{NPV}=\sum_{t=0}^{n} \frac{B t}{(1+i)^{t}}-\sum_{t=0}^{n} \frac{C t}{(1+i)^{t}}=\sum_{t=0}^{n} \frac{B t-C t}{(1+i)^{t}}
$$


Keterangan :

$\mathrm{Bt}=$ penerimaan (benefit) pada tahun ke-t

$\mathrm{Ct}=$ biaya (cost) pada tahun ke- $\mathrm{t}$

$\mathrm{n}$ = umur ekonomis proyek (tahun)

$\mathrm{i}=$ tingkat suku bunga (\%)

$\mathrm{t}=$ tahun

Kriterian penilaian :

(a) Bila NPV >0, maka investasi dinyatakan layak (feasible)

(b) Bila NPV < 0, maka investasi dinyatakan tidak layak (no feasible)

(c) Bila NPV $=0$, maka investasi berada pada posisi break event point

\section{c. Internal Rate Of Return (IRR)}

$$
\text { IRR }=i_{1}+\frac{N P V 1}{N P V 1-N P V 2} \times\left(i_{2}-i_{1}\right)
$$

Keterangan :

NPV1 = present value positif

NPV2 = present value negative

$\mathrm{i}_{1} \quad=$ discount factor, jika NPV $>0$

$\mathrm{i}_{2} \quad=$ discount factor, jika NPV $<0$

Kriteria penilaian :

(a) Jika IRR > i, maka kegiatan usaha layak untuk dilaksanakan

(b) Jika IRR < i, maka kegiatan usaha tidak layak untuk dilaksanakan

(c) Jika IRR = i, maka kegiatan usaha dalam keadaan break event point

\section{d. Gross Benefit Cost Ratio (Gross B/C)}

Keterangan :

$$
\text { Gross B/C }=\frac{\sum_{t=0}^{n} \frac{B_{t}}{(1+i)^{t}}}{\sum_{t=0}^{n} \frac{C_{t}}{(1+i)^{t}}}
$$

$\mathrm{Bt}=$ penerimaan (benefit) pada tahun ke-t

$\mathrm{Ct}=$ biaya (cost) pada tahun ke- $\mathrm{t}$

$\mathrm{n} \quad=$ umur ekonomis proyek (tahun)

$\mathrm{i} \quad=$ tingkat suku bunga (\%)

$\mathrm{t}=$ tahun

Kriteria penilaian :

(a) Jika Gross $\mathrm{B} / \mathrm{C}>1$, maka usaha tersebut layak untuk diusahakan

(b) Jika Gross B/C < 1,maka usaha tersebut tidak layak untuk diusahakan

(c) Jika Gross $\mathrm{B} / \mathrm{C}=1$, maka usaha tersebut dalam keadaan break event point

\section{e. Net Benefit Cost Ratio (Net B/C)}

$$
\text { Net } \mathrm{B} / \mathrm{C}=\frac{\sum_{t=0}^{n} \frac{B t-C t}{(1+i)^{t}} \text { Untuk Bt }-\mathrm{Ct}>\mathbf{0}}{\sum_{t=0}^{n} \frac{C t-B t}{(1+i)^{t}} \text { Untuk Bt }-\mathrm{Ct}<0}
$$

Keterangan :

$\mathrm{Bt}=$ penerimaan (benefit) pada tahun ke-t

$\mathrm{Ct}=$ biaya (cost) pada tahun ke-t

$\mathrm{n} \quad=$ umur ekonomis proyek (tahun)

$\mathrm{i}=$ tingkat suku bunga (\%)

$\mathrm{t} \quad=$ tahun

Kriteria penilaian :

(a) Jika NetB/C > 1, maka usaha tersebut layak untuk diusahakan

(b) Jika Net B/C < 1, maka usaha tersebut tidak layak untuk diusahakan

(c) Jika Net $\mathrm{B} / \mathrm{C}=1$, maka usaha tersebut dalam keadaan break event point

\section{f. Payback Period (PP)}

Payback Period $=n+\frac{(a-b)}{(c-b)} x 1$ Tahun

Keterangan :

$\mathrm{PP}=$ tahun pengembalian investasi

$\mathrm{n}=$ tahun terakhir di mana arus kas masih belum bisa menutupi initial investment

$\mathrm{a}=$ jumlah initial investment

$\mathrm{b}=$ jumlah kumulatif arus kas pada tahun ke- $\mathrm{n}$

$\mathrm{c} \quad=$ jumlah kumulatif arus kas pada tahun ke- $\mathrm{n}+1$

Kriteria kelayakan :

(a) Jika Payback Period lebih pendek dari umur ekonomis usaha, maka proyek tersebut layak untuk dijalankan.

(b) Jika Payback Period lebih lama dari umur ekonomis usaha, maka proyek tersebut tidak layak untuk dijalankan.

\section{HASIL DAN PEMBAHASAN}

Gambaran Umum Usahatani Kelapa Sawit Ibu Hj. Sunarsih

\section{Pembukaan Lahan}

Awal pembukaan lahan usahatani kelapa sawit Ibu Hj. Sunarsih pada luasan lahan 10 ha dibuka pada tahun 2009. Pembukaan lahan dilakukan dengan cara menebang kayu, menebas semak belukar, dan menyemprot rumput serta gulma-gulma yang berada di area lahan. Setelah lahan rata terbakar bersih, barulah diratakan dan dibersihkan kembali 
dengan alat berat seperti Ekskavator yang dilakukan untuk membuat akses jalan ke lahan agar bisa di akses dengan mudah nantinya. Setelah lahan bersih dan sudah siap, barulah bisa dilakukan untuk persiapan penanam bibit tanaman kelapa sawit.

\section{Penanaman}

Pada usahatani kelapa sawit Ibu $\mathrm{Hj}$. Sunarsih penanaman dilakukan pada tahun 2009 dan bibit yang digunakan adalah bibit unggul jenis Lonsum yang diperoleh dari PT. Uni Primacom dengan harga Rp 26.000 per bibit dan sudah memiliki usia 1-1,5 tahun serta siap untuk ditanam. Jumlah populasi (pohon) usahatani kelapa sawit milik Ibu Hj. Sunarsih di Desa Karya Bersama berjumlah 1.200 pohon dengan jumlah per hektar 120 pohon. Berdasarkan hasil penelitian jumlah populasi (pohon) usahatani Kelapa Sawit Rakyat milik Ibu Hj. Sunarsih ada sebanyak 120 Pohon/Ha dengan jarak tanam $9 \mathrm{~m} \times 9 \mathrm{~m}$ $\mathrm{x} 9 \mathrm{~m}$.

\section{Pemeliharaan}

Pemeliharaan tanaman kelapa sawit Ibu Hj. Sunarsih di Desa Karya Bersama yaitu : a. Piringan

Piringan dilakukan di sekitar lahan tanaman kelapa sawit berfungsi sebagai tempat untuk menyebarkan pupuk agar efisien diserap tanaman. Selain itu, piringan juga merupakan daerah jatuhnya buah kelapa sawit. Berdasarkan hasil penelitian pada usahatani kelapa sawit Ibu $\mathrm{Hj}$. Sunarsih pengaplikasian piringan hanya dilakukan 1 kali dalam setahun.

b. Pemupukan

Pada awal usahatani kelapa sawit Ibu $\mathrm{Hj}$. Sunarsih pemupukan dilakukan sebanyak 3-4 kali dan setelah tanaman mulai menghasilkan pemupukan hanya dilakukan 2-3 kali. Berdasarkan hasil penelitian saat ini pemupukan yang dilakukan oleh $\mathrm{Ibu} \mathrm{Hj}$. Sunarsih menggunakan pupuk NPK Phonska. Pemupukan dilakukan 2 kali dalam satu tahun. Total pupuk NPK yang digunakan dalam 2 kali aplikasi yaitu 7.200 $\mathrm{Kg}$ /Tahun dengan rata-rata per $\mathrm{Ha} 720$ $\mathrm{Kg} /$ Tahun atau $6 \mathrm{Kg}$ /Pohon/Tahun.

c. Penyemprotan

Berdasarkan hasil penelitian saat ini merek herbisida yang sering digunakan Ibu
Hj. Sunarsih yaitu Gramoxone dan Metafuron yang dibeli sendiri. Merek herbisida ini dipakai karena dapat digunakan pada lahan kering dan lahan basah, kemudian penggunaan pestisida dilakukan sebanyak 1-2 dua kali pengaplikasiannya dalam satu tahun. Total penggunaan herbisida yang terdiri dari Gramoxone sebesar 40 Liter/Tahun atau 4 Liter/Ha/Tahun dan Metafuron sebagai campuran Gramoxone sebesar 750 Gram/Tahun atau $75 \mathrm{Gram} / \mathrm{Ha} / \mathrm{Tahun}$.

\section{d. Pruning}

Pruning merupakan salah satu pekerjaan kultur teknis yang diperlukan dalam upaya peningkatan produktivitas kelapa sawit. Pruning dilakukan untuk mempermudah pekerjaan panen, menghindari tersangkutnya brondolan pada ketiak pelepah, memperlancar proses penyerbukan alami, mempermudah pengamatan buah matang pada saat pekerjaan panen, melakukan sanitasi (kebersihan) tanaman untuk menciptakan lingkungan yang tidak sesuai bagi perkembangan hama dan penyakit, pada tanaman muda (tunas pasir) mempermudah pemupukan, pembersihan piringan, dan pengutipan brondolan. Berdasarkan hasil penelitian saat pada usahatani Ibu $\mathrm{Hj}$. Sunarsih pruning dilakukan sebanyak 2 kali dalam setahun.

\section{Tenaga Kerja}

Penggunaan Tenaga Kerja dalam usahatani Kelapa Sawit Ibu Hj. Sunarsih di Desa Karya Bersama memiliki jumlah tenaga kerja saat ini sebanyak 5-6 orang yang berasal dari kalangan dalam keluarga sebanyak 3 orang dan luar keluarga 2-3 orang. Berdasarkan hasil penelitian saat ini tenaga kerja usahatani Kelapa Sawit Ibu $\mathrm{Hj}$. Sunarsih yaitu terdiri dari tenaga kerja piringan, tenaga kerja pengangkut pupuk, tenaga kerja pemupukan, tenaga kerja penyemprotan, tenaga kerja pruning, tenaga kerja pemanenan, dan tenaga kerja pengangkut TBS (Tandan Buah Segar).

\section{Pemanenan}

Berdasarkan hasil penelitian saat ini kelapa sawit Ibu $\mathrm{Hj}$. Sunarsih di Desa 
Karya Bersama untuk luas lahan 10 ha (tahun tanam 2009) memiliki produksi pada tahun 2020 sebesar $252.000 \mathrm{Kg}$ TBS dengan tingkat produktivitas sebesar $25.200 \mathrm{Kg} / \mathrm{ha}$ atau 25,2 Ton/ha. Produktivitas Kelapa Sawit ini relatif cukup tinggi, jika dibandingkan dengan produktivitas Kelapa Sawit sesuai umur tanam menurut Pusat Penelitian Kelapa Sawit (2017) yaitu hanya sebesar 20.830 $\mathrm{Kg} / \mathrm{Ha}$ atau 20,83 Ton/Ha untuk usia tanam 11 tahun. Secara umum faktor-faktor yang mempengaruhi produksi Kelapa Sawit adalah luas lahan, jumlah populasi (pohon), umur tanaman, perawatan tanaman, dan tenaga kerja.

\section{Pemasaran}

Hasil panen Kelapa Sawit milik Ibu $\mathrm{Hj}$. Sunarsih dijual ke perusahaan PT. Uni Primacom karena sudah menjadi pelanggan tetap, selain itu juga karena jangkauan terdekat untuk penjualan Tandan Buah Segar (TBS) dengan pertimbangan untuk meminimalisir biaya angkut penjualannya. Berdasarkan hasil penelitian harga produksi Tandan Buah Segar (TBS) Ibu Hj. Sunarsih mengacu pada harga rata-rata per bulan yang telah ditetapkan oleh PT Uni Primacom pada tahun 2020 .

\section{Analisis Kelayakan Finansial Usaha Kelapa Sawit Rakyat}

\section{Analisis Arus Kas (Cash Flow Analysis)}

\section{a. Analisis Biaya Usahatani Kelapa Sawit Ibu Hj. Sunarsih di Desa Karya Bersama}

Tabel 5.1. Biaya Awal (Initial Investment) Usahatani Kelapa Sawit Ibu Hj. Sunarsih Di Desa Karya Bersama

\begin{tabular}{llrrr}
\hline No. & \multicolumn{1}{c}{ Uraian } & Harga Satuan $(\mathbf{R p})$ & Jml & \multicolumn{1}{c}{ Total (Rp) } \\
\hline 1. & Biaya Lahan & 10.000 .000 & 10 & 100.000 .000 \\
2. & Pembukaan Lahan dan Penanaman & 1.000 .000 & 8 & 8.000 .000 \\
3. & Cangkul & 150.000 & 6 & 900.000 \\
4. & Parang & 150.000 & 6 & 900.000 \\
5. & Egrek & 150.000 & 5 & 750.000 \\
6. & Dodos & 150.000 & 6 & 900.000 \\
7. & Gancu & 100.000 & 6 & 600.000 \\
8. & Tojok & 100.000 & 5 & 500.000 \\
9. & Angkong & 350.000 & 6 & 2.100 .000 \\
10. & Semprotan (Sprayer) & 200.000 & 5 & 1.000 .000 \\
11. & Bibit & 26.000 & 1.200 & 31.200 .000 \\
12. & Pengangkutan Bibit & & - & 1.980 .000 \\
\hline \multicolumn{2}{c}{ Total Biaya Investasi } \\
\hline
\end{tabular}

Sumber: Data Primer yang Diolah, 2020

Berdasarkan Tabel 5.1 dapat dilihat bahwa biaya awal (initial investment) usahatani kelapa sawit Ibu Hj. Sunarsih di Desa Karya Bersama adalah sebesar Rp 148.830.000. Biaya investasi yang terbesar yaitu biaya lahan sebesar Rp 100.000.000 dengan luasan lahan sebesar 10 ha. untuk biaya operasional yang merupakan biaya keseluruhan yang berhubungan dengan kegiatan operasional dari usahatani kelapa sawit Ibu $\mathrm{Hj}$. Sunarsih selama 11 tahun usia tanam yang meliputi biaya pupuk, biaya 
obat-obatan (pestisida), dan biaya tenaga

kerja dapat dilihat pada Tabel 1.

Tabel 1. Biaya Operasional Usahatani Kelapa Sawit Ibu Hj. Sunarsih Di Desa Karya Bersama

\begin{tabular}{crrrr}
\hline Tahun & $\begin{array}{c}\text { Biaya Pupuk } \\
\text { (Rp/Ha/Tahun) }\end{array}$ & $\begin{array}{c}\text { Biaya Pestisida } \\
\text { (Rp/Ha/Tahun) }\end{array}$ & $\begin{array}{c}\text { Biaya Tenaga } \\
\text { Kerja } \\
\text { (Rp/Ha/Tahun) }\end{array}$ & $\begin{array}{c}\text { Total Biaya } \\
\text { Operasional } \\
\text { (Rp/Ha/Tahun) }\end{array}$ \\
\hline 0 & 2.160 .000 & 3.310 .000 & 13.406 .000 & 18.876 .000 \\
1 & 2.880 .000 & 3.310 .000 & 13.406 .000 & 19.596 .000 \\
2 & 3.840 .000 & 3.630 .000 & 16.248 .000 & 23.718 .000 \\
3 & 8.640 .000 & 3.930 .000 & 18.264 .000 & 30.834 .000 \\
4 & 6.840 .000 & 3.850 .000 & 37.195 .000 & 47.885 .000 \\
5 & 7.800 .000 & 3.960 .000 & 41.995 .000 & 53.755 .000 \\
6 & 16.560 .000 & 1.995 .000 & 47.770 .000 & 66.325 .000 \\
7 & 16.560 .000 & 1.995 .000 & 57.610 .000 & 76.165 .000 \\
8 & 18.000 .000 & 2.210 .000 & 69.540 .000 & 89.750 .000 \\
9 & 18.000 .000 & 2.210 .000 & 89.220 .000 & 109.430 .000 \\
10 & 24.480 .000 & 2.425 .000 & 95.922 .000 & 122.827 .000 \\
11 & 27.360 .000 & 2.425 .000 & 105.762 .000 & 135.547 .000 \\
\hline Jumlah & $\mathbf{1 5 3 . 1 2 0 . 0 0 0}$ & $\mathbf{3 5 . 2 5 0 . 0 0 0}$ & $\mathbf{6 0 6 . 3 3 8 . 0 0 0}$ & $\mathbf{7 9 4 . 7 0 8 . 0 0 0}$ \\
\hline
\end{tabular}

Sumber: Data Primer Diolah, 2020

Berdasarkan Tabel 5.2 dapat dilihat bahwa total biaya operasional usahatani kelapa sawit Ibu $\mathrm{Hj}$. Sunarsih di Desa Karya Bersama selama 11 tahun sebesar Rp 794.708.000.

Total cost yang dikeluarkan untuk usahatani kelapa sawit Ibu $\mathrm{Hj}$. Sunarsih selama produksi 11 tahun adalah sebesar Rp 943.538.000 yang berasal dari investasi awal (Initial Investmen) sebesar $\mathrm{Rp}$ 148.830.000 yang dapat dilihat pada Tabel 5.1 dan biaya operasional sebesar $\mathrm{Rp}$ 794.708.000 pada Tabel 2.

\section{b. Analisis Penerimaan Usahatani Kelapa Sawit Ibu Hj. Sunarsih di Desa Karya Bersama}

Tabel 2. Produksi Tandan Buah Segar (TBS) dan Penerimaan Usahatani Kelapa Sawit Ibu Hj. Sunarsih

\begin{tabular}{rcrcr}
\hline Tahun & $\begin{array}{c}\text { Produksi } \\
(\mathrm{Kg})\end{array}$ & $\begin{array}{c}\text { Potongan Produksi } \\
(2 \%)\end{array}$ & $\begin{array}{c}\text { Produksi Bersih } \\
(\mathrm{Kg})\end{array}$ & Penerimaan Bersih (Rp) \\
\hline 2009 & - & - & - & - \\
2010 & - & - & - & - \\
2011 & - & - & - & - \\
2012 & - & - & - & - \\
2013 & 84.000 & 1.680 & 82.320 & 103.654 .600 \\
2014 & 108.000 & 2.160 & 105.840 & 144.780 .300 \\
2015 & 132.000 & 2.640 & 129.360 & 167.240 .920 \\
2016 & 156.000 & 3.120 & 152.880 & 220.898 .860 \\
2017 & 180.000 & 3.600 & 176.400 & 253.901 .900 \\
2018 & 204.000 & 4.080 & 199.920 & 263.770 .920 \\
2019 & 228.000 & 4.560 & 223.440 & 378.383 .880 \\
2020 & 252.000 & 5.040 & 246.960 & $\mathbf{1 . 8 1 3 . 6 6 3 . 4 6 0}$ \\
\hline Total & $\mathbf{1 . 3 4 4 . 0 0 0}$ & $\mathbf{2 6 . 8 8 0}$ & $\mathbf{1 . 3 1 7 . 1 2 0}$ & \\
\hline
\end{tabular}


Berdasarkan Tabel 5.3 dapat dilihat bahwa produksi Tandan Buah Segar (TBS) pada usahatani Ibu $\mathrm{Hj}$. Sunarsih selama 11 tahun adalah sebanyak 1.344.000 Kg. Setelah dikenakan potongan produksi sebesar $2 \%$ dari PT. Uni Primacom, produksi bersih Tandan Buah Segar (TBS) yang diterima Ibu $\mathrm{Hj}$. Sunarsih selama 11 tahun adalah sebanyak $1.317 .120 \mathrm{Kg}$ dengan total penerimaan yang didapat selama periode 11 tahun usaha Rp 1.813.663.460.

\section{c. Keuntungan Usahatani Kelapa Sawit Ibu Hj. Sunarsih di Desa Karya Bersama}

Manfaat (benefit) dapat dinyatakan sebagai keuntungan (profit) proyek. Keuntungan (profit) adalah total penerimaan yang dikurangi dengan total biaya yang dikeluarkan. Sehingga keuntungan usahatani kelapa sawit Ibu Hj. Sunarsih di Desa Karya Bersama selama 11 tahun diperoleh keuntungan usaha sebagai berikut:

$$
\begin{aligned}
\pi & =\text { TR }- \text { TC } \\
& =\operatorname{Rp} 1.813 .663 .460-\operatorname{Rp} 943.538 .000 \\
& =\operatorname{Rp} 870.125 .460
\end{aligned}
$$

Jadi pada usahatani kelapa sawit Ibu $\mathrm{Hj}$. Sunarsih memperoleh keuntungan usaha sebesar Rp 870.125.460 atau dengan rata-rata memperoleh keuntungan sekitar Rp 108.765.682,5 per tahun.

\section{Net Present Value (NPV)}

Tabel 5.4. Perhitungan Net Present Value (NPV)

\begin{tabular}{ccccccrr}
\hline T* & $\begin{array}{c}\text { Total Biaya } \\
\text { (Rp) }\end{array}$ & $\begin{array}{c}\text { Penerimaan } \\
\text { (Rp) }\end{array}$ & $\begin{array}{c}\text { Penerimaan } \\
\text { Bersih (Rp) }\end{array}$ & $\begin{array}{c}\text { DF } \\
\mathbf{6 \%}\end{array}$ & Pv B (Rp) & Pv C (Rp) & $\begin{array}{c}\text { Pv Net Benevit } \\
\text { (Rp) }\end{array}$ \\
\hline 0 & 167.706 .000 & - & -167.706 .000 & 1 & - & 167.706 .000 & -167.706 .000 \\
1 & 19.596 .000 & - & -19.596 .000 & 0,943 & - & 18.479 .028 & -18.479 .028 \\
2 & 23.718 .000 & - & -23.718 .000 & 0,890 & - & 21.109 .020 & -21.109 .020 \\
3 & 30.834 .000 & - & -30.834 .000 & 0,840 & - & 25.900 .560 & -25.900 .560 \\
4 & 47.885 .000 & 103.654 .600 & 55.769 .600 & 0,792 & 82.094 .443 & 37.924 .920 & 44.169 .523 \\
5 & 53.755 .000 & 144.780 .300 & 91.025 .300 & 0,747 & 108.150 .884 & 40.154 .985 & 67.995 .899 \\
6 & 66.325 .000 & 167.240 .920 & 100.915 .920 & 0,705 & 117.904 .849 & 46.759 .125 & 71.145 .724 \\
7 & 76.165 .000 & 220.898 .860 & 144.733 .860 & 0,665 & 146.897 .742 & 50.649 .725 & 96.248 .017 \\
8 & 89.750 .000 & 281.901 .900 & 192.151 .900 & 0,627 & 176.752 .491 & 56.273 .250 & 120.479 .241 \\
9 & 109.430 .000 & 253.032 .080 & 143.602 .080 & 0,592 & 149.794 .991 & 64.782 .560 & 85.012 .431 \\
10 & 122.827 .000 & 263.770 .920 & 140.943 .920 & 0,558 & 147.184 .173 & 68.537 .466 & 78.646 .707 \\
11 & 135.547 .000 & 378.383 .880 & 242.836 .880 & 0,527 & 199.408 .305 & 71.433 .269 & 127.975 .036 \\
\hline & & & & NPV & $\mathbf{1 . 1 2 8 . 1 8 7 . 8 7 8}$ & $\mathbf{6 6 9 . 7 0 9 . 9 0 8}$ & $\mathbf{4 5 8 . 4 7 7 . 9 7 0}$ \\
\hline
\end{tabular}

Sumber: Data Primer yang Diolah, 2020

Berdasarkan hasil perhitungan nilai

Net Present Value (NPV) yang dapat dilihat pada Tabel 5.4, menunjukan bahwa usahatani kelapa sawit Ibu $\mathrm{Hj}$. Sunarsih di Desa Karya Bersama diperoleh hasil nilai NPV sebesar Rp 458.477.970 yang berarti nilai NPV bernilai positif dan sesuai dengan kriteria yaitu NPV > 0. Maka dari itu nilai tersebut menunjukkan bahwa usahatani kelapa sawit Ibu Hj. Sunarsih di Desa Karya Bersama menguntungkan karena hasil yang diperoleh lebih besar dari pada biaya yang dikeluarkan, sehingga layak untuk dilaksanakan atau dilanjutkan. Hasil penelitian ini tidak jauh berbeda dengan hasil penelitian Demiyati dan Priatna (2012) yang menunjukkan nilai NPV > 0 , yaitu sebesar Rp 983.132.527,25 dan hasil 
penelitian Utomo, dkk (2018) yang juga menunjukkan nilai NPV > 0, yaitu sebesar Rp 150.497.126.

\section{Internal Rate Of Return (IRR)}

Tabel 5.5. Perhitungan Internal Rate of Return (IRR)

\begin{tabular}{crrrrr}
\hline Tahun & $\begin{array}{c}\text { Pv Net Benevit } \\
(\mathbf{R p})\end{array}$ & \multicolumn{1}{c}{$\begin{array}{c}\text { DF } \\
\mathbf{1 6} \%\end{array}$} & $\begin{array}{c}\text { Pv Net Benevit } \\
(\mathbf{R p})\end{array}$ & $\begin{array}{c}\text { DF } \\
\mathbf{1 7} \%\end{array}$ & $\begin{array}{c}\text { Pv Net Benevit } \\
(\mathbf{R p})\end{array}$ \\
\hline 0 & -167.706 .000 & 1 & -167.706 .000 & 1 & -167.706 .000 \\
1 & -18.479 .028 & 0,862 & -15.928 .922 & 0,855 & -15.799 .569 \\
2 & -21.109 .020 & 0,743 & -15.684 .002 & 0,731 & -15.430 .694 \\
3 & -25.900 .560 & 0,641 & -16.602 .259 & 0,624 & -16.161 .949 \\
4 & 44.169 .523 & 0,552 & 24.381 .577 & 0,534 & 23.586 .525 \\
5 & 67.995 .899 & 0,476 & 32.366 .048 & 0,456 & 31.006 .130 \\
6 & 71.145 .724 & 0,410 & 29.169 .747 & 0,390 & 27.746 .832 \\
7 & 96.248 .017 & 0,354 & 34.071 .798 & 0,333 & 32.050 .590 \\
8 & 120.479 .241 & 0,305 & 36.746 .169 & 0,285 & 34.336 .584 \\
9 & 85.012 .431 & 0,263 & 22.358 .269 & 0,243 & 20.658 .021 \\
10 & 78.646 .707 & 0,227 & 17.852 .802 & 0,208 & 16.358 .515 \\
11 & 127.975 .036 & 0,195 & 24.955 .132 & 0,178 & 22.779 .556 \\
\hline Total & $\mathbf{4 5 8 . 4 7 7 . 9 7 0}$ & NPV 1 & $\mathbf{5 . 9 8 0 . 3 5 9}$ & $\mathbf{N P V ~ 2}$ & $\mathbf{- 6 . 5 7 5 . 4 5 9}$ \\
\hline
\end{tabular}

Sumber: Data Primer yang Diolah, 2020

Berdasarkan Tabel 5.5 hasil perhitungan IRR (Internal Rate of Return) usahatani kelapa sawit Ibu $\mathrm{Hj}$. Sunarsih di Desa Karya Bersama adalah $16,48 \%$. Nilai tersebut lebih besar dari suku bunga $6 \%$, karena nilai IRR lebih besar dari suku bunga maka usahatani kelapa sawit Ibu $\mathrm{Hj}$. Sunarsih di Desa Karya Bersama dinyatakan layak atau memberikan manfaat selama umur proyek yang diperhitungkan. IRR yang dihitung adalah berdasarkan NPV 1 dan NPV 2 berdasarkan hasil percobaan dari asumsi dua diskon faktor yang kemudian diinterpolasi sehingga mendapatkan hasil sebesar 16,48 \%. Hasil penelitian ini tidak jauh berbeda dengan hasil penelitian Putri, dkk (2013) yang menunjukkan nilai IRR > i, yaitu sebesar $24,034 \%$ dan hasil penelitian Pujiharti dan Hafif (2013) yang juga menunjukkan nilai IRR > i, yaitu sebesar $53 \%$.

\section{Gross Benefit Cost Ratio (Gross B/C)}

Gross B/C pada usahatani kelapa sawit Ibu $\mathrm{Hj}$. Sunarsih di Desa Karya Bersama didapatkan hasil sebesar 1,68 pada diskon faktor sebesar $6 \%$. Gross B/C bernilai 1,68 atau Gross B/C > 1 yang artinya proyek memberikan keuntungan bahwa setiap pengeluaran sebesar Rp 1,00 maka akan memberikan manfaat bersih sebesar $\operatorname{Rp} 1,68$. Nilai tersebut menunjukkan usahatani kelapa sawit Ibu Hj. Sunarsih di Desa Karya Bersama layak untuk dijalankan. Hasil penelitian ini tidak jauh berbeda dengan hasil penelitian Pasaribu, dkk (2013) yang menunjukkan nilai Gross B/C > 1, yaitu sebesar 1,6616 dan hasil penelitian Affandi dan Alfizar (2016) yang juga menunjukkan nilai Gross B/C > 1, yaitu sebesar 5,61.

\section{Net Benefit Cost ratio (Net B/C)}

Net B/C merupakan penilaian yang dilakukan untuk melihat tingkat efisiensi penggunaan biaya usahatani kelapa sawit Ibu Hj. Sunarsih di Desa Karya Bersama yang berupa perbandingan jumlah nilai bersih sekarang yang positif dengan jumlah nilai bersih sekarang yang negatif. Berdasarkan hasil analisis Net B/C usahatani kelapa sawit Ibu $\mathrm{Hj}$. Sunarsih di Desa Karya Bersama didapatkan hasil sebesar 2,97 yang menunjukkan manfaat 
bersih yang diperoleh setiap penambahan satu rupiah pengeluaran bersih. Nilai tersebut menunjukkan usahatani kelapa sawit Ibu $\mathrm{Hj}$. Sunarsih di Desa Karya Bersama layak untuk dijalankan. Hasil penelitian ini tidak jauh berbeda dengan hasil penelitian Demiyati dan Priatna (2012) yang menunjukkan nilai Net B/C > 1, yaitu sebesar 3,70 dan hasil penelitian hasil penelitian Affandi dan Alfizar (2016) yang juga menunjukkan nilai $\mathrm{Net} \mathrm{B} / \mathrm{C}>1$, yaitu sebesar 24,84 .

\section{Payback Period (PP)}

\section{Tabel 5.6. Perhitungan Payback Period (PP)}

\begin{tabular}{cccccrrr}
\hline $\mathbf{T}^{*}$ & $\begin{array}{c}\text { Biaya } \\
\text { Investasi } \\
(\mathbf{R p})\end{array}$ & $\begin{array}{c}\text { Biaya } \\
\text { Operasional } \\
(\mathbf{R p})\end{array}$ & $\begin{array}{c}\text { Total Biaya } \\
(\mathbf{R p})\end{array}$ & $\begin{array}{c}\text { ?enerimaan } \\
(\mathbf{R p})\end{array}$ & $\begin{array}{r}\text { nerimaan Bersih } \\
(\mathbf{R p})\end{array}$ & Arus Kas $(\mathbf{R p )})$ & $\left(\mathbf{T}^{*}\right)$ \\
\hline 0 & $\mathbf{1 4 8 . 8 3 0 . 0 0 0}$ & 18.876 .000 & 167.706 .000 & - & -167.706 .000 & -167.706 .000 \\
1 & & 19.596 .000 & 19.596 .000 & - & -19.596 .000 & -187.302 .000 \\
2 & & 23.718 .000 & 23.718 .000 & - & -23.718 .000 & -211.020 .000 \\
3 & & 30.834 .000 & 30.834 .000 & - & -30.834 .000 & -241.854 .000 \\
4 & & 47.885 .000 & 47.885 .000 & 103.654 .600 & 55.769 .600 & -186.084 .400 \\
5 & & 53.755 .000 & 53.755 .000 & 144.780 .300 & 91.025 .300 & -95.059 .100 & \\
$\mathbf{6}$ & & $\mathbf{6 6 . 3 2 5 . 0 0 0}$ & $\mathbf{6 6 . 3 2 5 . 0 0 0}$ & $\mathbf{1 6 7 . 2 4 0 . 9 2 0}$ & $\mathbf{1 0 0 . 9 1 5 . 9 2 0}$ & $\mathbf{5 . 8 5 6 . 8 2 0}$ & $\mathbf{6}$ \\
7 & & 76.165 .000 & 76.165 .000 & 220.898 .860 & 144.733 .860 & 150.590 .680 & \\
8 & & 89.750 .000 & 89.750 .000 & 281.901 .900 & 192.151 .900 & 342.742 .580 & \\
9 & & 109.430 .000 & 109.430 .000 & 253.032 .080 & 143.602 .080 & 486.344 .660 & \\
10 & & 122.827 .000 & 122.827 .000 & 263.770 .920 & 140.943 .920 & 627.288 .580 & \\
11 & & 135.547 .000 & 135.547 .000 & 378.383 .880 & 242.836 .880 & 870.125 .460 & \\
\hline Total & $\mathbf{1 4 8 . 8 3 0 . 0 0 0}$ & $\mathbf{7 9 4 . 7 0 8 . 0 0 0}$ & $\mathbf{9 4 3 . 5 3 8 . 0 0 0}$ & $\mathbf{1 . 8 1 3 . 6 6 3 . 4 6 0}$ & $\mathbf{8 7 0 . 1 2 5 . 4 6 0}$ & & \\
\hline
\end{tabular}

Sumber: Data Primer yang Diolah, 2020

Berdasarkan Tabel 5.6 hasil perhitungan Payback Period pada usahatani kelapa sawit Ibu $\mathrm{Hj}$. Sunarsih di Desa Karya Bersama adalah sebesar 6,98 yang artinya tingkat pengembalian modal investasi adalah 6 tahun 11 bulan. Umur proyek usahatani kelapa sawit Ibu $\mathrm{Hj}$. Sunarsih adalah 11 tahun dan tingkat pengembalian modal masih dalam umur proyek yaitu 6 tahun 11 bulan, maka usaha dapat dikatakan layak. Hasil penelitian ini tidak jauh berbeda dengan hasil penelitian Affandi dan Alfizar (2016) yang menunjukkan nilai Payback Period sebesar 6,24 tahun dan hasil penelitian Maisaroh, dkk (2017) yang juga menunjukkan nilai nilai Payback Period sebesar 6,4 tahun.

\section{KESIMPULAN}

1. Usahatani Kelapa Sawit Rakyat Ibu Hj. Sunarsih di Desa Karya Bersama pada luasan lahan 10 hektar hanya memiliki populasi sebanyak 1.200 pohon dengan jumlah pohon per hektar sebanyak 120 pohon dan jarak tanam yang digunakan sudah sesuai dengan standar jarak tanam yang dianjurkan Pusat Penelitian Kelapa Sawit (PPKS) yaitu $9 \mathrm{~m} \times 9 \mathrm{~m} \times 9 \mathrm{~m}$. Bibit sawit yang digunakan adalah salah satu bibit unggul dengan jenis Lonsum yang diperoleh dari PT. Uni Primacom dengan harga Rp 26.000 per bibit dan sudah memiliki usia 1-1,5 tahun serta siap untuk ditanam. Pemupukan yang dilakukan sudah teratur yaitu saat masa awal tanam dilakukan sebanyak 3-4 kali pengaplikasian dalam setahun dan setelah tanaman mulai menghasilkan pemupukan yang dilakukan 2-3 kali pengaplikasian dalam setahun. Pada tahun 2020 kelapa sawit Ibu $\mathrm{Hj}$. Sunarsih memiliki produksi sebesar $252.000 \mathrm{Kg}$ TBS dengan tingkat produktivitas sebesar $25.200 \mathrm{Kg} / \mathrm{ha}$ atau 25,2 Ton/ha, Produktivitas ini relatif cukup 
tinggi, jika dibandingkan dengan produktivitas Kelapa Sawit sesuai umur tanam menurut Pusat Penelitian Kelapa Sawit (2017) yaitu hanya sebesar 20.830 $\mathrm{Kg} / \mathrm{Ha}$ atau 20,83 Ton/Ha untuk usia tanam 11 tahun. Jumlah tenaga kerja yang dimiliki Ibu $\mathrm{Hj}$. Sunarsih saat ini sebanyak 5-6 orang yang berasal dari kalangan dalam keluarga sebanyak 3 orang dan luar keluarga sebanyak 2-3 orang. Hasil panen Tandan Buah Segar (TBS) usahatani kelapa sawit Ibu Hj. Sunarsih dijual ke perusahaan PT. Uni Primacom yang sudah menjadi pelanggan tetap.

2. Usahatani kelapa sawit Ibu $\mathrm{Hj}$. Sunarsih di Desa Karya Bersama selama periode 11 tahun tanam layak untuk diusahakan dan dilanjutkan dengan penilaian kriteria investasi pada diskon faktor $6 \%$ yang merupakan suku bunga KUR Mikro Bank BRI pada tahun 2020, didapatkan hasil perhitungan sebagai berikut :

- $\quad$ Nilai NPV > 0 Rp 458.477.970

- $\quad$ Nilai IRR > i yaitu $16,48 \%$

- $\quad$ Nilai Gross B/C > 1 yaitu 1,68

- $\quad$ Nilai Net B/C > 1 yaitu 2,97

- $\quad$ Payback Period sebesar 6,98 (6 tahun 11 bulan)

Hasil penilaian menunjukkan bahwa usahatani kelapa sawit Ibu $\mathrm{Hj}$. Sunarsih di Desa Karya Bersama tersebut layak secara finansial untuk melanjutkan usahatani yang sudah dilaksanakan, karena nilai NPV, IRR, Gross B/C, Net B/C dan Payback Period menunjukkan usaha tersebut sudah memenuhi penilaian kriteria investasi pada analisis kelayakan finansial dan pengembalian investasi yang juga cepat yaitu terjadi pada 6,98 tahun atau 6 tahun 11 bulan setelah usahatani kelapa sawit Ibu Hj. Sunarsih berjalan. 